\title{
Antibiograma como análise da sensibilidade in vitro de Corynebacterium pseudotuberculosis de caprinos
}

\author{
Antibiogram as an in vitro sensitivity analysis of \\ Corynebacterium pseudotuberculosis from caprines
}

Clarissa Vitória Silva Lopes ${ }^{[a]}$, Marialice Rocha Guimarães Rosa ${ }^{[a]}$, Mirna Ribeiro dos Santos ${ }^{[a]}$,Victor Pereira Curvelo ${ }^{[a]}$, Daniel Pedreira da Cunha $a^{[a]}$, Eduardo Farias Guerra ${ }^{[a]}$, Maurício Costa Alves da Silva $a^{[b]}$, Darcy Pires de Matos Pinheiro ${ }^{[c]}$ e Robson Bahia Cerqueira ${ }^{[d]}$

[a] Graduandos em Medicina Veterinária da União Metropolitana para o Desenvolvimento da Educação e Cultura (UNIME), Salvador, BA - Brasil, e-mail: clarissavitoria@gmail.com

[b] Professor Doutor do Departamento de Medicina Veterinária Preventiva, Laboratório de Inspeção e Tecnologia de Carnes e Derivados da Universidade Federal da Bahia (UFBA), Salvador, BA - Brasil.

[c] Professor Mestre do Departamento de Microbiologia Veterinária da União Metropolitana para o Desenvolvimento da Educação e Cultura (UNIME), Salvador, BA - Brasil.

[d] Professor Doutor do Departamento de Doenças Infecciosas da União Metropolitana para o Desenvolvimento da Educação e Cultura (UNIME), Salvador, BA - Brasil, e-mail: robsonba@gmail.com

\section{Resumo}

Corynebacterium pseudotuberculosis é um microrganismo Gram-positivo, imóvel, não esporulado, de importância na Medicina Veterinária por se tratar do agente etiológico da linfadenite caseosa. Esta é uma doença infecciosa crônica de distribuição mundial que acomete, principalmente, caprinos e ovinos. 0 presente estudo objetivou avaliar o perfil de sensibilidade antimicrobiana in vitro de 41 isolados de Corynebacterium pseudotuberculosis de caprinos de regiões do semiárido baiano frente a 20 antimicrobianos. Encontrou-se 100\% de cepas sensíveis à florfenicol; 93\% à tetraciclina; 88\% à norfloxacina, enrofloxacina, gentamicina, tobramicina, bacitracina e azitromicina; $85 \%$ à clindamicina, cefalexina e eritromicina; $83 \%$ à ciprofloxacina, penicilina G, rifampicina e cefaclor; $80 \%$ a sulfazotrim; $78 \%$ à ampicilina; $71 \%$ à estreptomicina; $63 \%$ à ceftriaxona e $2 \%$ à novobiocina. Observou-se diferença no perfil de sensibilidade entre linhagens bacterianas laboratoriais e selvagens, sendo estas últimas mais resistentes. Concluiu-se que as linhagens laboratoriais foram resistentes à novobiocina e as linhagens selvagens apresentaram maior resistência à novobiocina, estreptomicina e ceftriaxona.

Palavras-chave: Pequenos ruminantes. Caprinos. Linfadenite caseosa. Corynebacterium pseudotuberculosis. Antibiograma.

\section{Abstract}

Corynebacterium pseudotuberculosis is a Gram positive microorganism, non-motile, non-sporulating of great importance to veterinary medicine as it is the causative agent of caseous lymphadenitis. It is a worldwide 
distribution chronic infectious disease that affects mainly sheeps and goats. This study aimed to evaluate the profile of in vitro antimicrobial susceptibility of 41 Corynebacterium pseudotuberculosis isolates from goats raised in Bahia's semiarid region in contact with 20 antimicrobial drugs. All the isolates (100\%) were susceptible to florfenicol, 93\% to tetracycline, 88\% to norfloxacin, enrofloxacin, gentamicin, tobramycin, bacitracin and azithromycin, $85 \%$ to clindamycin, erythromycin and cephalexin, $83 \%$ to ciprofloxacin, penicillin $G$ in the rifampin and cefaclor; $80 \%$ to sulfatrim, 78\% to ampicillin, 71\% to streptomycin, $63 \%$ to ceftriaxone and $2 \%$ to novobiocin. In general, wild bacterial isolates were more resistant to antibiotics than laboratory strains. Moreover, laboratory strains were resistant to novobiocin and wild strains showed higher resistance to novobiocin, streptomycin and ceftriaxone.

Keywords: Small ruminants. Goats. Caseous lymphadenitis. Corynebacterium pseudotuberculosis. Antibiogram.

\section{Introdução}

A linfadenite caseosa é uma doença infectocontagiosa crônica, causada por Corynebacterium pseudotuberculosis, que afeta principalmente caprinos e ovinos. Além destes, pode acometer outros animais domésticos, causando dermatite ulcerativa em equinos e linfangite ulcerativa em bovinos. É considerada uma zoonose ocupacional que acomete profissionais ligados à criação de caprinos e ovinos (MOURA-COSTA, 2002; PATON, et al., 2003; RIBEIRO et al., 2001). Nozaki et al. (2000) relataram que os animais clinicamente afetados apresentam formação de piogranulomas caseosos nos linfonodos, principalmente os retrofaríngeos, mandibulares, parotídeos, cervicais superficiais, subilíacos e mamários.

O microrganismo apresenta-se como coco-bacilo Gram-positivo, podendo apresentar-se isolado, formando grupamentos irregulares ou em paliçada. São anaeróbios facultativos, não formadores de esporos, fermentadores de açúcares e imóveis (MOURA-COSTA, 2002).

Por serem microrganismos intracelulares, os granulomas são encapsulados e a resposta é ineficiente. Abreu et al. (2008) e Radostits et al. (2002) afirmam que o tratamento não costuma ser tentado, embora haja relatos na literatura atestando a eficácia in vitro de alguns antimicrobianos contra o agente etiológico e o microrganismo seja sensível à penicilina e outros antibióticos.

A caprinocultura é uma atividade que vem se destacando no território nacional, especialmente nas regiões semiáridas dos estados nordestinos, sendo uma das principais atividades econômicas de pequenos produtores rurais, como mencionam Ribeiro et al. (1988). Dessa forma, a linfadenite caseosa é um problema crucial, uma vez que a sua ocorrência pode causar debilidade dos animais; comprometimento da pele, condenação de carcaças e órgãos internos; diminuição da produção de leite; problemas reprodutivos, como redução na fertilidade; submissão de riscos à saúde pública; e custos com o diagnóstico da doença e tratamento das lesões, gerando, dessa maneira, prejuízos econômicos relevantes, e culminando, ocasionalmente, com o abate para descartar os animais severamente afetados (ALVES; OLANDER, 1999; CONNOR et al., 2000; PINHEIRO Jr. et al., 2006).

O objetivo deste trabalho foi avaliar o perfil de sensibilidade antimicrobiana in vitro das cepas de Corynebacterium pseudotuberculosis isoladas de caprinos procedentes de regiões semiáridas da Bahia (Brasil), frente a 20 diferentes drogas disponíveis comercialmente, buscando confirmar os resultados encontrados na literatura sobre o assunto.

\section{Materiais e métodos}

Foram utilizadas amostras de linhagens de Corynebacterium pseudotuberculosis previamente identificadas e mantidas congeladas a $-70^{\circ} \mathrm{C}$ em laboratório, e também amostras coletadas a campo de caprinos naturalmente acometidos pela linfadenite caseosa na região do semiárido baiano.

Do total de 41 amostras, 23 foram cedidas pelo Laboratório de Microbiologia do Instituto de 
Ciências da Saúde (ICS) da UFBA - Universidade Federal da Bahia. Trata-se de material proveniente de caprinos (com mais de 1 ano de idade), originados das regiões de Juazeiro, Curaçá e Remanso, BA, todos apresentando granulomas característicos em linfonodos submandibulares, pré-escapulares, parotídeos, retromamários e flanco. Essas amostras foram coletadas de 1971 a 2010 e armazenadas em freezer a $-70{ }^{\circ} \mathrm{C}$. As demais linhagens (18) foram coletadas diretamente de caprinos, sem raça definida, machos e fêmeas, com idade variando entre 8 e 36 meses, naturalmente infectados em propriedades particulares na região do semiárido baiano.

A maioria das coletas, totalizando 34 amostras, ocorreu em uma propriedade particular localizada no município de Capim Grosso, cujas atividades pecuárias são voltadas para a caprinocultura de corte, bem como bovinocultura de corte e leite. Essas coletas foram divididas em duas visitas durante os meses de fevereiro e março de 2010. Dentro das linhagens coletadas, apenas 18 apresentaram características compatíveis com o Corynebacterium pseudotuberculosis e somente estas foram utilizadas neste trabalho.

A caprinocultura na propriedade apresenta uma média de 800 animais, com manejo extensivo e alimentação típica de caatinga, sal mineral e água $a d$ libitum, que também recebem imunoproteção anual contra clostridioses e vermifugação trimestral. Os animais foram selecionados a partir da divisão do rebanho em grupos e, então, inspecionados e selecionados a partir da presença de granulomas em linfonodos superficiais. Na maioria dos casos, os pré-escapulares foram os mais acometidos, seguidos pelos retrofaríngeos e submandibulares. A coleta foi realizada por meio de tricotomia do local com lâmina estéril, subsequente antissepsia com álcool a $70 \%$, seguida por iodo a $10 \%$.

Realizou-se uma incisão vertical no granuloma, com bisturi estéril descartável, e o material caseoso foi, então, armazenado em coletor universal estéril previamente identificado, imediatamente acondicionado em gelo. Após a coleta de todo o material do granuloma, foi realizada a limpeza interna da região cirúrgica com pinça hemostática curva e gaze embebida em iodo a 10\%. Em seguida, aplicou-se sobre a pele da lesão um medicamento bactericida, cicatrizante e repelente à base de sulfadiazina prata, alumínio micronizado e cipermetrina (Bactrovet ${ }^{\circledR}$ Prata).
Para a realização dos antibiogramas, foram utilizados 20 discos de antimicrobianos $(6,35 \mathrm{~mm})$ usados na clínica médica de grandes animais (laboratório CEFAR ${ }^{\circledR}$ Diagnóstica Ltda.- SP). As drogas usadas foram: tetraciclina $(30 \mu \mathrm{g})$; cefalexina $(30 \mu \mathrm{g})$; cefaclor $(30 \mu \mathrm{g})$; eritromicina $(15 \mu \mathrm{g})$; norfloxacina $(10 \mu \mathrm{g})$; clindamicina $(2 \mu \mathrm{g})$; bacitracina (10UI); azitromicina $(15 \mu \mathrm{g})$; gentamicina $(10 \mu \mathrm{g})$; estreptomicina $(10 \mu \mathrm{g})$; penicilina G (10UI); ceftriaxona $(30 \mu \mathrm{g})$; tobramicina $(10 \mu \mathrm{g})$; rifampicina $(5 \mu \mathrm{g})$; ciprofloxacina $(5 \mu \mathrm{g})$; ampicilina $(10 \mu \mathrm{g})$; novobiocina $(5 \mu \mathrm{g})$; florfenicol $(30 \mu \mathrm{g})$; enrofloxacina $(5 \mu \mathrm{g})$; sulfazotrim $(1,25 \mu \mathrm{g} / 23,75 \mu \mathrm{g})$. Os discos de antibióticos de ciprofloxacina, enrofloxacina, norfloxacina, estreptomicina, gentamicina, penicilina G, eritromicina, sulfa com trimetropim, tetraciclina, novobiocina, ampicilina e clindamicina foram escolhidos com base na literatura e os demais foram selecionados com base no uso da rotina do LADI - Laboratório de Doenças Infecciosas (ABREU et al., 2008; JUDSON; SONGER, 1991; PRESCOTT; YIELDING, 1990; RIBEIRO et al., 2001; ZHAO et al., 1991).

0 material caseoso coletado foi semeado com uma alça de platina, por meio da técnica de estrias, próximo ao bico de Bunsen em placas de Petri, contendo ágar sangue de carneiro a $10 \%$. Posteriormente, elas foram levadas à estufa em aerobiose a $37{ }^{\circ} \mathrm{C}$ por 48 horas. Doze das linhagens laboratoriais (C. Amarela; AM260; VD21; VD28; VD29; VD31; VD37; VD39; VD43¹; VD52; VD57; VD58) não apresentaram crescimento no período informado, sendo necessário realizar mais que dois repiques em meio seletivo (caldo $\mathrm{BHI}$ ) para reativação e obtenção do crescimento característico, totalizando um período de 96 a 120 horas.

Passado o período, procedeu-se a leitura das placas em que as colônias características de Corynebacterium pseudotuberculosis se apresentaram com coloração amarelo-esbranquiçada, secas, pequenas, puntiformes ou homogêneas, sem odor, facilmente deslocadas com a alça de platina através do ágar e com discreta hemólise. A partir das colônias características, foram realizadas as colorações de Gram e Ziehl-Neelsen. As provas bioquímicas realizadas foram catalase, lactose, manose, frutose e glicose, com os seguintes resultados: todas as amostras foram catalase positivas e glicose positivas; nenhuma amostra fermentou lactose, manose ou frutose. De acordo com Dorella et al. (2006), 
Corynebacterium pseudotuberculosis produz ácido, sem produção de gás, a partir de carboidratos, como, por exemplo: glicose, frutose, maltose e sacarose. As amostras cocoides Gram-positivas, BAAR negativas e catalase positivas foram consideradas como Corynebacterium pseudotuberculosis e, então, repicadas para caldo $\mathrm{BHI}$ e levadas à incubação aeróbica em estufa a $37^{\circ} \mathrm{C}$ por mais 48 horas.

Após esse período, foi procedida a leitura dos tubos de ensaio e observado um crescimento na superfície, de aspecto flocoso e sem turvação do meio, facilmente desfeito e precipitado se agitado. A partir desse material, foram realizados os antibiogramas.

Em placas de Petri contendo ágar BHI, foram adicionados $200 \mu \mathrm{L}$ do cultivo em caldo BHI, anteriormente analisado de acordo com as características já descritas, contendo crescimento do microrganismo previamente incubado, por meio de micropipeta de valor fixo, próximo à chama produzida pelo bico de Bunsen. Em seguida, o líquido foi disseminado, ainda próximo ao fogo, com o auxílio da alça de Drigalski. As placas foram incubadas em estufa bacteriológica a $37^{\circ} \mathrm{C}$ durante uma hora.

Passado esse tempo, dentro do fluxo laminar, por meio de uma pinça anatômica previamente esterilizada, foram distribuídos quatro discos de antibióticos $\left(\right.$ Cefar $\left.^{\circledR}\right)$ por cada placa de Petri, totalizando cinco placas a cada amostra, que depois foram incubadas a $37{ }^{\circ} \mathrm{C}$ durante 48 horas.

0 fluxo laminar foi previamente desinfetado com álcool a 70\%, forrado com papel Kraft, arrumado com uma pinça e dois pares de luvas de procedimentos, e manteve-se a lâmpada germicida ligada durante 30 minutos. Após o período de esterilização, a lâmpada germicida foi desligada e foram, então, acionados o ventilador e a iluminação. Logo após, foi executada a técnica de realização dos antibiogramas, que constituiu na colocação de quatro discos de antibióticos por placa, em distância equivalente entre os mesmos.

0 teste de sensibilidade aos antimicrobianos foi realizado seguindo-se a técnica de difusão com discos adotada na rotina do LADI - Laboratório de Doenças Infecciosas (BAUER et al., 1966).

Após 48 horas de incubação em estufa a $37{ }^{\circ} \mathrm{C}$, as placas foram retiradas e foi procedida a leitura dos halos de inibição para todo disco de antibiótico de cada uma das amostras. Os halos de inibição foram medidos em milímetros, por meio de uma régua graduada, e os valores foram anotados. Após cada leitura, os resultados foram analisados de acordo com a bula dos discos fornecida pelo fabricante, identificando os antimicrobianos aos quais o microrganismo apresentou resultados de sensibilidade, sensibilidade intermediária ou resistência.

\section{Resultados}

Das 41 linhagens avaliadas por meio do teste de sensibilidade antimicrobiana in vitro, verificou-se que todas apresentaram sensibilidade a pelo menos 1 das 20 drogas testadas, 10 apresentaram sensibilidade intermediária a, pelo menos, 1 droga e 41 linhagens apresentaram resistência a, pelo menos, 1 droga.

Dentre as dez linhagens que apresentaram sensibilidade intermediária a alguma droga, duas (20\%) foram linhagens cultivadas e mantidas armazenadas em laboratório, enquanto oito (80\%) foram linhagens bacterianas selvagens.

Dos 20 antimicrobianos testados, 6 (30\%) tiveram as 23 linhagens bacterianas laboratoriais testadas apresentando sensibilidade a florfenicol, tetraciclina, norfloxacina, enrofloxacina, azitromicina e gentamicina.

Na avaliação das linhagens bacterianas selvagens, todas as cepas apresentaram sensibilidade in vitro ao florfenicol. Dentre as 41 linhagens bacterianas analisadas que apresentaram sensibilidade a alguma droga, 38 (93\%) apresentaram sensibilidade à tetraciclina.

Grande parte das linhagens bacterianas laboratoriais apresentou sensibilidade à maioria dos antimicrobianos testados in vitro, com exceção da novobiocina, à qual todas as linhagens foram resistentes. Observa-se que apenas duas linhagens apresentaram resultado de sensibilidade intermediária, sendo uma a ciprofloxacina e outra a estreptomicina (Gráfico 1).

Percebeu-se um número maior de linhagens bacterianas selvagens resistentes e com sensibilidade intermediária a mais de um antibiótico. Houve a constatação de que todas as linhagens estudadas apresentaram sensibilidade ao florfenicol, e a maioria (16) apresentou resistência à novobiocina, com apenas uma linhagem sensível a este mesmo antimicrobiano. Cinco linhagens apresentaram sensibilidade intermediária à estreptomicina (Gráfico 2).

Em relação à sensibilidade à estreptomicina, 21 (92\%) das linhagens bacterianas laboratoriais demonstraram-na, 1 (4\%) apresentou sensibilidade 


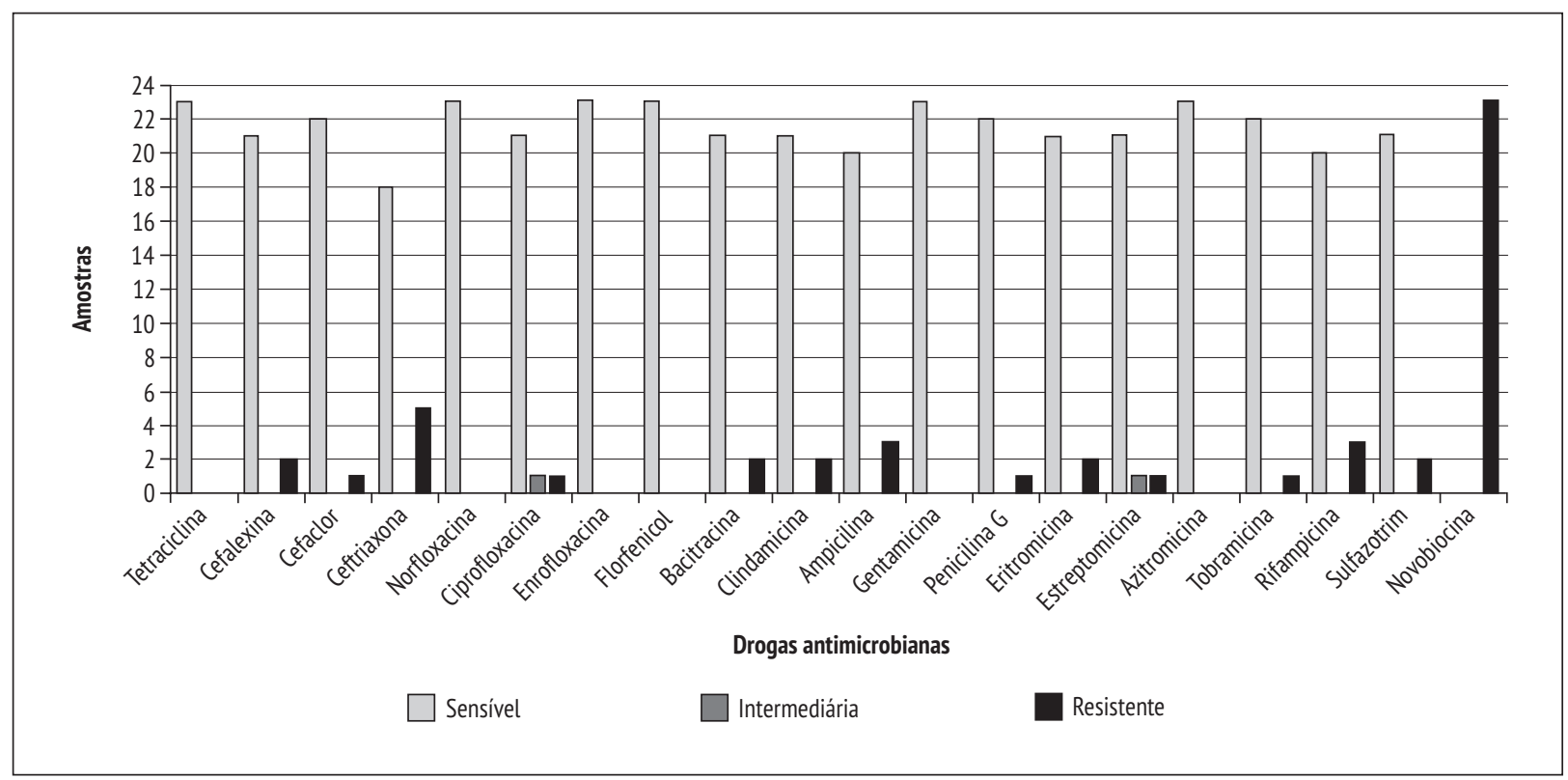

Gráfico 1 - Sensibilidade in vitro a 20 antimicrobianos de linhagens laboratoriais ( $\mathrm{n}=23$ ) de Corynebacterium pseudotuberculosis provenientes de caprinos, Bahia, 2011

Fonte: Dados da pesquisa.

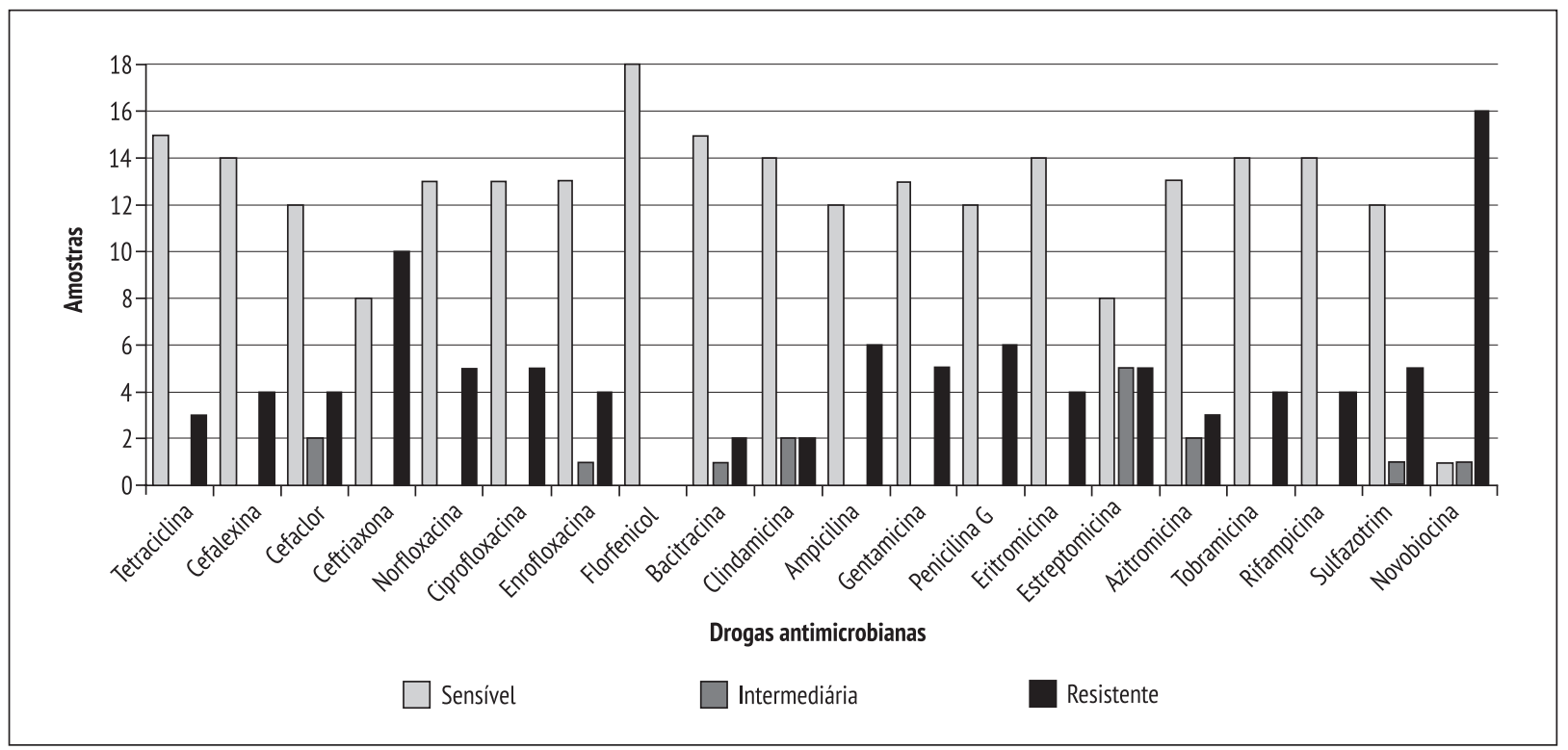

Gráfico 2 - Sensibilidade in vitro a 20 antimicrobianos de linhagens selvagens $(\mathrm{N}=18)$ de Corynebacterium pseudotuberculosis provenientes de caprinos, Bahia, 2011

Fonte: Dados da pesquisa.

intermediária e 1 (4\%) apresentou-se resistente. Em relação às linhagens bacterianas selvagens, 8 (44\%) linhagens se apresentaram sensíveis, 5 (28\%) com sensibilidade intermediária e 5 (28\%) resistentes.
Um (4\%) dos 20 antimicrobianos testados, a novobiocina, teve todas as linhagens bacterianas laboratoriais apresentando resistência. Em relação às linhagens bacterianas selvagens, 16 (88\%) foram 
resistentes, $1(6 \%)$ foi sensível e $1(6 \%)$ apresentou sensibilidade intermediária a esse antibiótico.

Em relação à penicilina G, 22 (96\%) das linhagens bacterianas laboratoriais apresentaram sensibilidade, enquanto 1 (4\%) apresentou resistência e $12(67 \%)$ das linhagens bacterianas selvagens se apresentaram sensíveis, enquanto 6 (33\%) foram resistentes.

Quanto à ceftriaxona, 18 (78\%) das linhagens bacterianas laboratoriais foram sensíveis, enquanto $5(22 \%)$ foram resistentes, 8 (44\%) sensíveis e $10(56 \%)$ resistentes.

Dentre as 23 linhagens bacterianas laboratoriais, duas se destacaram. A linhagem VD31 foi a única que apresentou sensibilidade intermediária, o que ocorreu em relação à estreptomicina e à ciprofloxacina. Já a linhagem AM267 se apresentou resistente a $12(60 \%)$ dos antimicrobianos avaliados.

Dentre as linhagens bacterianas selvagens, sete se destacaram. A linhagem C10 se mostrou resistente a $10(50 \%)$ das drogas avaliadas; a C17 foi resistente a 11 (55\%); a C19 e a C20 foram resistentes a 15 (75\%); a C23 foi resistente a 16 (85\%) e a C31 não foi resistente a nenhum dos 20 antibióticos testados.

Há ocorrência de linhagens mais agressivas, como a linhagem selvagem C23, que apresentou sensibilidade a apenas três drogas (florfenicol, clindamicina e bacitracina), e a linhagem laboratorial AM267, que foi sensível a apenas 8 das 20 drogas testadas, sendo estas: florfenicol, tetraciclina, enrofloxacina, norfloxacina, tobramicina, estreptomcina, gentamicina e azitromicina. As citadas linhagens diferem, ainda, quanto ao padrão de sensibilidade, quando demonstram resistência à penicilina G e rifampicina, que foram drogas que apresentaram notável sensibilidade das outras linhagens estudadas.

\section{Discussão}

A partir da análise dos resultados, observou-se que as linhagens bacterianas selvagens apresentaram maior número de cepas com sensibilidade intermediária às drogas avaliadas, em relação às linhagens bacterianas de laboratório. Tal fato indicou menor susceptibilidade aos antimicrobianos por linhagens obtidas de lesões de animais naturalmente infectados, sugerindo maior resistência antimicrobiana por parte das linhagens bacterianas selvagens.
Houve diferenças entre as linhagens analisadas, com variação entre linhagens laboratoriais, linhagens selvagens, e laboratoriais e selvagens.

Resultados concordantes com os deste trabalho foram encontrados por Muckle e Gyles (1982), que avaliaram a sensibilidade antimicrobiana in $v i-$ tro de 25 linhagens de Corynebacterium pseudotuberculosis isoladas de lesões de caprinos e estas apresentaram susceptibilidade à gentamicina, tetraciclina, penicilina e sulfadiazina/trimetroprim. Concordando com os demais autores, as linhagens avaliadas apresentaram resistência à estreptomicina. Neste estudo, não foi observada resistência expressiva em relação às linhagens avaliadas frente a ela, pois $21(92 \%)$ das linhagens bacterianas laboratoriais demonstraram sensibilidade a esta droga. Todavia, no caso das linhagens bacterianas selvagens analisadas, a estreptomicina não demonstra grande eficácia, pois dez (56\%) das linhagens apresentaram resistência, o que se aproxima dos resultados dos demais autores.

Prescott e Yielding (1990) investigaram a sensibilidade antimicrobiana in vitro de diversos patógenos de importância médico veterinária à enrofloxacina, ciprofloxacina e norfloxacina. Em sua avaliação, as linhagens estudadas de Corynebacterium pseudotuberculosis apresentaram sensibilidade similar à enrofloxacina e ciprofloxacina e sensibilidade moderada à norfloxacina. Nota-se que esses dados não estão de acordo com os encontrados neste trabalho, em relação às mesmas drogas, pois nele, a enrofloxacina e norfloxacina apresentaram resultados de sensibilidade superiores aos resultados encontrados de sensibilidade à ciprofloxacina na avaliação das linhagens bacterianas laboratoriais. Na avaliação das linhagens bacterianas selvagens, as três drogas em questão apresentaram resultados de sensibilidade semelhantes.

Neste estudo, foram encontrados resultados parcialmente concordantes com o realizado por Judson e Songer (1991), no qual foi percebida alta sensibilidade das linhagens testadas a drogas como tetraciclina, azitromcina, clindamicina, penicilina, cefalosporinas, clorfenicol e rifampicina. Em relação à alta sensibilidade percebida pelos autores, o presente trabalho mostra um dado discordante, pois em relação às cefalosporinas estudadas (cefalexina, cefaclor e ceftriaxona), a ceftriaxona apresentou grande número de linhagens bacterianas resistentes, 
especialmente as selvagens. No presente trabalho, não foi utilizado cloranfenicol, em função da proibição de sua utilização em animais de produção; e no lugar dessa droga, utilizou-se florfenicol, que apresentou excelentes resultados, previamente discutidos. Em relação ao estudo dos referidos autores, foi encontrada sensibilidade menos expressiva à bacitracina, o que difere deste trabalho, no qual essa droga apresentou boa sensibilidade in vitro frente à maioria das linhagens bacterianas testadas. Judson e Songer encontraram as linhagens testadas resistentes à estreptomicina, o que discorda deste trabalho, no qual houve linhagens sensíveis a essa droga. Em relação à novobiocina, os autores relataram alta sensibilidade, o que discorda dos resultados do presente trabalho, no qual as linhagens apresentaram 95\% de resistência à referida droga.

Os resultados descritos neste trabalho são parcialmente concordantes com o estudo realizado por Zhao et al. (1991), em relação a algumas das drogas testadas, no qual a maioria das linhagens de Corynebacterium pseudotuberculosis avaliadas apresentaram marcante sensibilidade antimicrobiana a penicilina G, ampicilina e bacitracina, dados iguais aos encontrados neste trabalho. Também houve grande número de linhagens suscetíveis a outras drogas, como gentamicina, tetraciclina, clindamicina e trimetropim, o que difere deste trabalho apenas no que se refere à gentamicina, droga que não apresentou sensibilidade tão expressiva em comparação às demais. Todas as linhagens apresentaram resistência à sulfadiazina, dado que discorda parcialmente dos encontrados nesta pesquisa, na qual sulfazotrim (associação de sulfadiazina com trimetropim) demonstrou resultados de sensibilidade pela maioria das linhagens bacterianas testadas.

Observou-se que a novobiocina é uma droga à qual a maioria das linhagens bacterianas, tanto laboratoriais quanto selvagens, apresentou resistência. Assim, para a propriedade avaliada, não se justifica a utilização desse fármaco para o tratamento da linfadenite caseosa, com base nos resultados encontrados no teste in vitro. Zhao et al. (1991) obtiveram resultados semelhantes ao analisarem linhagens de Corynebacterium pseudotuberculosis, observando que a novobiocina foi a droga que apresentou a maior parte das linhagens estudadas resistentes.

Neste trabalho, percebeu-se que há drogas mais eficazes contra linhagens de Corynebacterium pseudoturbeculosis na análise in vitro, sendo elas: florfenicol, tetraciclina, norfloxacina, enrofloxacina e gentamicina, às quais todas as linhagens mantidas em laboratório apresentaram sensibilidade e, assim, se destacam, sugerindo maior eficácia. Além das linhagens bacterianas laboratoriais avaliadas, todas as linhagens bacterianas selvagens apresentaram sensibilidade in vitro ao florfenicol, sendo esta a única droga que apresentou $100 \%$ das linhagens bacterianas selvagens sensíveis, o que comprova a sua eficácia, in vitro, contra o agente etiológico da linfadenite caseosa em caprinos. Corrêa e Corrêa (1992) sugeriram uma terapêutica a partir da associação de antibióticos aos quais o Corynebacterium pseudotuberculosis apresenta sensibilidade, e o DMSO (dimetilsulfóxido), pois afirmam que, assim, foram encontrados resultados satisfatórios no tratamento de enfermidades semelhantes à linfadenite caseosa, no que diz respeito à dificuldade de tratamento. Vale salientar que o dimetilsulfóxido apresenta potencial cancerígeno, tendo a sua utilização proibida para animais de produção em países da Europa.

Soriano et al. (1995) testaram a susceptibilidade antimicrobiana in vitro de espécies de Corynebacterium sp. frente a 18 antimicrobianos, e encontraram dados concordantes com este trabalho ao verificarem uma ótima sensibilidade das linhagens de Corynebacterium pseudotuberculosis à rifampicina. Os autores encontraram a maioria das suas linhagens avaliadas sensíveis à eritromicina, tetraciclina, azitromicina, clindamicina, ciprofloxacina, ampicilina e gentamicina, dados que são parcialmente concordantes, uma vez que, neste estudo, encontramos menor sensibilidade das linhagens estudadas a drogas como ampicilina, gentamicina e eritromicina.

Outras drogas, como estreptomicina, ceftriaxona e novobiocina, apresentaram maior resistência, sendo que a estreptomicina apresentou, nesta pesquisa, maior resistência apenas por parte das linhagens bacterianas selvagens. Ribeiro et al. (2001) testaram sete linhagens de Corynebacterium pseudotuberculosis em relação à sensibilidade antimicrobiana in vitro frente a 15 antimicrobianos, dentre eles ciprofloxacina, enrofloxacina, estreptomicina, florfenicol, gentamicina, norfloxacina, penicilina $\mathrm{G}$, rifampicina, tetraciclina e sulfadiazina/trimetroprim, e encontraram resultados semelhantes aos deste trabalho, com a maioria das linhagens bacterianas avaliadas apresentando sensibilidade às drogas citadas. Ainda 
na avaliação desses autores, as linhagens estudadas apresentaram resistência à amicacina e estreptomicina. No presente trabalho, a amicacina não foi testada e a estreptomicina apresentou a maioria das linhagens laboratoriais sensíveis e a maioria das linhagens selvagens resistentes, dado discordante dos encontrados pelos autores citados há pouco.

Foi possível observar que 12 linhagens que sofreram sucessivos repiques (C. Amarela; AM260; VD21; VD28; VD29; VD31; VD37; VD39; VD43'; VD52; VD57; VD58) para se alcançar o crescimento necessário apresentaram determinada atenuação, o que pode ser ilustrado com uma maior sensibilidade frente às drogas testadas. Esse fato foi previamente divulgado por Meyer et al. (2002), ao observarem aumento na atenuação dos microrganismos utilizados para imunização de caprinos, quando estes sofreram repiques de culturas contínuas ou sucessivas ou após a liofilização.

Drogas como ciprofloxacina, penicilina G, rifampicina, tobramicina, bacitracina, clindamicina, ampicilina, sulfazotrim, cefaclor e cefalexina também apresentaram eficiência contra linhagens de Corynebacterium pseudotuberculosis, em menor proporção do que as outras drogas citadas anteriormente, mas igualmente com grande número de linhagens avaliadas, selvagens ou não, apresentando sensibilidade in vitro. Foram, do mesmo modo, encontrados por Merle et al. (2002) resultados de avaliação de sensibilidade antimicrobiana in vitro de linhagens de Corynebacterium pseudotuberculosis com sensibilidade à penicilina $\mathrm{G}$, tetraciclina e ampicilina e com resistência a estreptomicina.

\section{Conclusões}

Concluiu-se que há variações no perfil de sensibilidade das linhagens de Corynebacterium pseudotuberculosis provenientes da região do semiárido baiano frente aos antimicrobianos avaliados. 0 florfenicol, a enrofloxacina e a ciprofloxacina mostraram-se eficazes in vitro, assim como a penicilina G, gentamicina, cefaclor, rifampicina, azitromicina, tobramicina e clindamicina, que também apresentaram bons resultados. Observou-se, ainda, que há diferenças entre as linhagens de Corynebacterium pseudotuberculosis laboratoriais e selvagens e entre cada grupo em relação à sensibilidade aos antimicrobianos avaliados. Além disso, notaram-se variações entre linhagens coletadas de animais naturalmente infectados, as quais apresentaram resistência a um número maior de drogas. Sendo assim, foi constatada a impossibilidade de se iniciar a antibioticoterapia sem o conhecimento da eficácia das drogas.

\section{Referências}

ABREU, S. R. O. et al. Perfil de sensibilidade antimicrobiana in vitro de isolados de Corynebacterium pseudotuberculosis de caprinos e ovinos com linfadenite caseosa no sertão de Pernambuco, Brasil. Arquivo Brasileiro de Medicina Veterinária e Zootecnia, v. 15, p. 502-509, 2008.

ALVES, F. S. F.; OLANDER, H. J. Teste de pele em caprinos vacinados e infectados com Corynebacterium pseudotuberculosis. Pesquisa Agropecuária Brasileira, v. 34, p. 1313-1318, 1999.

BAUER, A. W. et al. Antibiotic susceptibility testing by standardized single disk method. American Journal of Clinical Pathology, v. 45, p. 493-496, 1966.

CONNOR, K. M. et al. Characterization of United Kingdom isolates of Corynebacterium pseudotuberculosis using pulsed-field gel electrophoresis. Journal of Clinical Microbiology, v. 38, p. 2633-2637, 2000.

CORRÊA, W. M.; CORRÊA, C. N. M. Enfermidades infecciosas dos mamíferos domésticos. 2. ed. Rio de Janeiro: MEDSI, 1992.

DORELLA, F. A. et al. Corynebacterium pseudotuberculosis: microbiology, biochemical properties, pathogenesis and molecular studies of virulence. Veterinary Research, v. 37, p. 201-218, 2006.

JUDSON, R.; SONGER, J. G. Corynebacterium pseudotuberculosis: in vitro susceptibility to 39 antimicrobial agents. Veterinary Microbiology, v. 27, p. 145-150, 1991.

MERLE, E. O. et al. Biofilm bacteria: formation and comparative susceptibility to antibiotics. The Canadian Journal of Veterinary Research, v. 66, p. 86-92, 2002.

MEYER, R. et al. Avaliação da resposta imune humoral em caprinos inoculados com uma vacina viva atenuada liofilizada contra Corynebacterium Pseudotuberculosis. Revista de Ciências Médicas e Biológicas, v. 1, p. 4248, 2002. 
MOURA-COSTA, L. F. Corynebacterium Pseudotuberculosis, o agente etiológico da Linfadenite Caseosa em caprinos. Revista de Ciências Médicas e Biológicas, v. 1, p. 105$115,2002$.

MUCKLE, C. A.; GYLES, C. L. Characterization of strains of Corynebacterium Pseudotuberculosis. Canadian Journal of Comparative Medicine and Veterinary Science, v. 46, p. 206-208, 1982.

NOZAKI, C. N.; FARIA, M. A. R.; MACHADO, T. M. M. Extirpação cirúrgica dos abcessos da Linfadenite Caseosa em caprinos. Arquivos do Instituto Biológico, v. 67, p. 187-189, 2000.

PATON, M. W.; WALKER, S. B.; WATT, G. F. Prevalence of caseous lymphadenitis and usage of caseous lymphadenitis vaccine in sheep flocks. Australian Veterinary Journal, v. 81, p. 91-95, 2003.

PINHEIRO Jr., J. W. et al. Corynebacterium pseudotuberculosis experimental infection of goats mamary gland. Arquivos do Instituto Biológico, v. 73, p. 395-400, 2006.

PRESCOTT, J. F.; YIELDING, K. M. In vitro susceptibility of selected veterinary bacterial pathogens to ciprofloxacin, enrofloxacin and norfloxacin. Canadian Journal of Veterinary Research, v. 54, p. 195-197, 1990.

RADOSTITS, O. M. et al. Clínica veterinária: um tratado de doenças dos bovinos, suínos, caprinos e equinos. Rio de Janeiro: Guanabara Koogan, 2002.
RIBEIRO, M. G. et al. Punção aspirativa com agulha fina no diagnóstico do Corynebacterium pseudotuberculosis na Linfadenite Caseosa. Arquivos do Instituto Biológico, v. 68, p. 23-28, 2001.

RIBEIRO, O. C. et al. Avaliação de vacina contra Linfadenite Caseosa em caprinos mantidos em regime extensivo. Pesquisa Veterinária Brasileira, v. 8, p. 27-29, 1988.

SORIANO, F.; ZAPARDIEL, J.; NIETO, E. Antimicrobial susceptibilities of Corynebacterium species and other non-spore-forming gram-positive bacilli to 18 antimicrobial agents. Antimicrobial Agents and Chemotherapy, v. 39, p. 208-214, 1995.

ZHAO, H. K. et al. Antimicrobial susceptibility of Corynebacterium pseudotuberculosis isolated from lesions of caseous lymphadenitis in sheep in Hokkaido, Japan. Journal Veterinary Medicine Science, v. 53, p. 355-356, 1991.

Recebido: 01/12/2010

Received: $12 / 01 / 2010$

Aprovado: $10 / 08 / 2011$

Approved: 08/10/2011 